\title{
Effects of a self-training program on shooting performance and kinematics in young basketball players: a case study \\ Efectos de un programa de autoentrenamiento sobre el rendimiento y cinemática de tiro en jóvenes jugadores de baloncesto: un caso de estudio
}

*Pedro Grenha, **José Moura, *Eduardo Guimarães, ***Pedro Fonseca, *Filipa Sousa, *Manuel Janeira *University of Porto (Portugal), **Sporting Clube de Braga-Basketball (Portugal), ***Porto Biomechanics Laboratory (Portugal)

\begin{abstract}
The current study intended to investigate the effects of a self-training program on shooting performance and kinematics of young basketball players. Fourteen male basketball players aged 16.64 \pm .50 years, divided in control group $(n=7)$ and experimental group $(n=7)$, were assessed on free-throw, two-point and three-point shooting performance and on four kinematic parameters (release height, release angle, release speed and trajectory variability), before and after a five-week training program. During the five-week period, the experimental group accomplished a shooting training program that included 600 shots per week. Both groups maintained their regular basketball practice. The results show that the experimental group significantly increased their shooting performance on three-point $(p<.05)$ and on free-throw $(p<.05)$. Moreover, a significant decrease in three-point ball release angle $(p<.05)$ and a significant increase in free-throw ball release height $(p<.05)$ were observed in the experimental group, while the control group significantly increased the two-point ball release speed $(p<.05)$. In conclusion, self-shooting basketball practice, in addition to formal practice, significantly improves shooting performance of young basketball players. In contrast, the reduced changes on the analysed kinematic parameters caused by the self-training program are most likely a consequence of the absence of external feedback during training process.
\end{abstract}

Keywords: basketball, self-training, shooting performance, kinematics, youth athletes

Resumen. El propósito del presente estudio fue investigar los efectos de un programa de autoentrenamiento en el rendimiento y cinemática de tiro de jóvenes jugadores de baloncesto. Catorce jugadores de baloncesto masculinos, de $16.64 \pm 0.50$ años, divididos en grupo de control $(n=7)$ y grupo experimental $(n=7)$, fueron evaluados en el rendimiento de tiro libre, de dos puntos y de tres puntos y en cuatro parámetros cinemáticos (altura de liberación, ángulo de liberación, velocidad de liberación y variabilidad de la trayectoria), antes y después de un programa de entrenamiento de cinco semanas. Durante el período de cinco semanas, el grupo experimental realizó un programa de entrenamiento de tiro que inclúá 600 tiros por semana. Ambos grupos mantuvieron su práctica regular de baloncesto. Los resultados muestran que el grupo experimental aumentó significativamente su rendimiento en el tiro de tres puntos $(p<.05)$ y en el tiro libre $(p<.05)$. Además, se observó, en el grupo experimental, una disminución significativa del ángulo de liberación en el tiro de tres puntos $(p<.05)$ y un aumento significativo de la altura de liberación en el tiro libre $(p<.05)$, mientras que el grupo de control aumentó significativamente la velocidad de liberación en el tiro de dos pontos $(p<.05)$. En conclusión, la autopráctica de tiro en baloncesto, además de la práctica formal, mejora significativamente el rendimiento de tiro de los jugadores jóvenes. Por el contrario, los cambios reducidos en los parámetros cinemáticos analizados son probablemente una consecuencia de la ausencia de corrección externa durante el proceso de autoentrenamiento.

Palabras clave: baloncesto, autoentrenamiento; rendimiento de tiro; cinemática; atletas jóvenes.

\section{Introduction}

Shooting is one of the most important technical skills in basketball (Doboviènik, Jakovljeviæ, Zovko \& Erèulj, 2015; Gaetano, Gaetano, Domenico \& Mario, 2016; Knudson, 1993; Satern, 1993) and one of the gamerelated statistics that best discriminate winning and losing teams (Èauševiæ, 2015; García, Ibáñez, Santos, Leite \&

Fecha recepción: 24-01-21. Fecha de aceptación: 01-07-21

Pedro Grenha

pm.grenha@hotmail.com
Sampaio, 2013; Ibáñez, García, Feu, Lorenzo \& Sampaio, 2009; Ibáñez, Sampaio, Sáenz-López, Giménez \& Janeira, 2003; Lorenzo, Gómez, Ortega, Ibáñez, \& Sampaio, 2010). Given its importance for success, several authors have been dedicated to investigate visual search strategies in basketball shooting (Uchida, Mizuguchi, Honda \& Kanosue, 2014), shooting performance (Ibáñez, Feu, García, Parejo \& Cañadas, 2009; Ibáñez, Santos \& García, 2015) and shooting kinematics from two different approaches: the trajectory of the ball and the shooter's kinematics (Ammar, Chtourou, Abdelkarim, Parish \& Hoekelmann, 2016; Doboviènik, et al., 2015; 
Elliott, 1992; Knudson, 1993; Maymin, Maymin \& Shen, 2012; Miller \& Bartlett, 1996; Satern, 1993; Verhoeven \& Newell, 2016).

The analysis of the trajectory of the ball in basketball shooting has identiûed the release height, release angle and release speed of the ball as the most determinant kinematic parameters for a successful outcome (Miller \& Bartlett, 1996). Changes in these three parameters of basketball shooting kinematics have been observed according to the distance from the shooter to the basket (Elliott \& White, 1989; Miller \& Bartlett, 1996; Okazaki, Lamas, Okazaki \& Rodacki, 2013; Okazaki \& Rodacki, 2012; Satern, 1993), players' specific position (Miller \& Bartlett, 1996), sex (Elliott, 1992), skill level (Button, MacLeod, Sanders \& Coleman, 2003; Okazaki, Rodacki \& Okazaki, 2006), shooting outcome (Mullineaux \& Uhl, 2010), fatigue level (Tsai, Ho, Lii \& Huang, 2006) and presence or absence of an opponent (Rojas, Cepero, Oña \& Gutierrez, 2000).

Additionally, research has been showing that the greater the release height of the ball during shooting, the less the distance that the ball has to travel in its trajectory to the basket with the consequent decrease of the force and speed required for technical execution (Okazaki, et al., 2006; Okazaki, Rodacki \& Satern, 2015; Tran, 2008). It is also suggested that the greater the release angle of the ball during shooting, the greater the angle of entry of the ball through the rim of the basket, increasing the chances of success (Doboviènik, et al., 2015; Miller \& Bartlett, 1996; Okazaki, et al., 2015). However, an increase in the angle of entry would also require the player to use a greater release angle and release speed (Doboviènik, et al., 2015; Okazaki, et al., 2006; Okazaki, et al., 2015). On the other hand, it seems that lower release speeds of the ball are related to greater movement accuracy and consistency (Mullineaux \& Uhl, 2010; Okazaki, et al., 2015). In short, a higher release height and release angle together with a lower release speed is the preferred combination when executing a successful basketball shot (Okazaki, et al., 2015). However, these parameters often show substantial inter-individual variability (Mullineaux \& Uhl, 2010), suggesting that there is no single ideal trajectory of the ball for a successful shot and that it always depends on the shooter characteristics (Gablonsky \& Lang, 2005; Hamilton \& Reinschmidt, 1997).

Literature is scarce regarding the intra-individual variability of shooting kinematics and its relationship with performance. Nevertheless, Schmidt (2012) refers that more experienced shooters show an increase in shooting pattern stability compared to less experienced shooters. In addition, Button et al. (2003) found that improvements in skill level are associated with an increasing amount of movement consistency from the elbow and wrist joints during shooting. In short, literature seems to suggest that the best shooters are more consistent and present lower variability between shots performed under identical conditions.

In addition to the contrast of the kinematic profiles between athletes of different levels, it is also important to know the effects of the training process on shooting performance and kinematics. Although some studies examine shooting performance improvement (Fazel, Morris, Watt \& Maher, 2018; Gómez, Kreivyte \& Sampaio, 2017), available literature regarding the effects of training on shooting kinematics is practically nonexistent. In fact, only Khlifa, Aouadi, Shephard, Chelly, Hermassi and Gabbett (2013), recently, applied a free-throw training program using a reduced diameter rim in which athletes significantly improved their freethrow shooting performance and significantly increased the ball release angle, speed and height and the shoulder joint angle at release.

Notwithstanding the importance of shooting performance to the final outcome of basketball games (Ėauševiæ, 2015; García, et al., 2013; Ibáñez, et al., 2003; Ibáñez, et al., 2009; Lorenzo, et al., 2010), empirical studies designed to understand the impact of training programmes on shooting kinematics are surprisingly scarce. Thus, intending to extend previous literature in this important topic, the present study aims to investigate the effects of a self-shooting training program, in addition to the formal practice, on both shooting performance and kinematics of under-18 male basketball players. Since most youth coaches do not have available time during team practices to increase basketball shooting volume, the implementation of a selfshooting training program may prove to be a useful strategy to improve kinematics and shooting efficiency. Therefore, we hypothesise that an increase of the training volume may cause changes in shooting kinematics, which could positively inûuence the trajectory of the ball and, consequently, the shooting performance.

\section{Methods}

\section{Experimental Approach to the Problem}

The present study was designed to investigate the effects of a five-week basketball shooting training program on shooting performance and kinematics of 
young basketball players. Two groups [experimental group (EG) and control group (CG)] were selected for this purpose. Both groups maintained their regular basketball practice, with the EG performing an additional five-week self-shooting training program. All participants were assessed on free-throw (FT), twopoint (2P) and three-point (3P) shooting performance, before (T0) and after (T1) the training program. The values corresponding to the kinematic parameters that describe the trajectory of the ball during shooting [release height (RH), release angle (RA), release speed (RS) and trajectory variability (TV)] were also determined at T0 and T1, for all players and for each type of shot. All players were assessed by the same team of evaluators between December 2016 and February 2017.

\section{Participants}

Fourteen young male basketball players from a team member of the Braga Basketball Association participated in this study. All players competed in the 2016/2017 under-18 XXI Portuguese National Championship, and practiced seven-nine hours/week. During the season, eight players regularly played in outside positions (i.e., guard and small forward) and six players regularly played in inside positions (i.e., power forward and center). For the study propose, players were randomly assigned into two groups (EG, $n=7$ and $C G, n=7$ ). Further sample characteristics are presented inTable 1 , and no significant $(p>.05)$ mean differences were found between groups. The club gave formal permission for data collection. Written informed consent was obtained from parents or legal guardians of each player, as well as players' individual assents. The study was approved by the Ethics Committee of the lead institution.

\begin{tabular}{|c|c|c|c|c|}
\hline Variable & $\begin{array}{c}\text { Experimental Group } \\
\qquad(n=7)\end{array}$ & $\begin{array}{c}\text { Control Group } \\
(n=7)\end{array}$ & $\mathrm{z}^{\dagger}$ & Effect size§ \\
\hline Age (years) & $16.71 \pm .49$ & $16.57 \pm .54$ & $-.54^{\mathrm{ns}}$ & 0.14 \\
\hline Training experience (years) & $7.71 \pm 3.86$ & $5.57 \pm 2.82$ & $-1.25^{\mathrm{ns}}$ & 0.39 \\
\hline Height $(\mathrm{cm})$ & $186.77 \pm 4.99$ & $188.93 \pm 5.31$ & $-.83^{\mathrm{ns}}$ & -0.27 \\
\hline Body mass $(\mathrm{kg})$ & $79.93 \pm 6.89$ & $77.70 \pm 8.54$ & $-.83^{\text {ns }}$ & 0.27 \\
\hline
\end{tabular}

biserial correlation; $n s=$ non-significant.

\section{Anthropometry}

Height $(\mathrm{cm})$ was measured without shoes and with the head positioned to the Frankfurt plane, using a stadiometer (Holtain Ltd., UK) with a precision of .01 $\mathrm{cm}$. Body mass $(\mathrm{kg})$ was measured with a digital scale (Tanita ${ }^{\circledR}$ HD-384, Tanita Corp., Japan) with a precision of $.01 \mathrm{~kg}$. All measurements were taken by experienced anthropometrists according to the International Working Group on Kinanthropometry protocols (Ross \& MarfellJones, 1995).

\section{Study Variables}

Shooting Performance

Basketball shooting performance was assessed with a test battery developed by Pojskic, Šeparovi and $U \bullet$ ianin (2011). The tests were performed at the team' training center, where the basketball court measurements, the backboard and the hoop are in accordance with the International Basketball Federation official rules (International Basketball Federation, 2014). The balls used in the tests were those adopted by the Portuguese Basketball Federation for men's under-18 2016/2017 season. All tests were performed in a single session with a five min recovery period between them. Prior to shooting testing protocol, the athletes accomplished 15 min of general warm up and specific basketball shooting drills. Shooting performance was assessed as follows:

(1) Free-throw shooting accuracy test: each player performed three series of ten FT, with a three min recovery period between series. Shooting position was marked on the floor at a distance of $4.05 \mathrm{~m}$ from the vertical projection of the hoop's center on the floor. Two other players, positioned below the hoop, caught the rebound and passed the ball back for a new shot. There was no time limit for performing the test;

(2) Two point shooting accuracy test: each player performed three series of ten $2 \mathrm{P}$ shots from five different positions, i.e. two jump shots from each position (Figure 1). There was a three min recovery period between each shooting series. Shooting positions were marked on the floor at a distance of five $\mathrm{m}$ from the vertical projection of the hoop's center on the floor. Two other players, positioned below the hoop, caught the rebound and passed the ball back for a new shot. There was no time limit for performing the test;

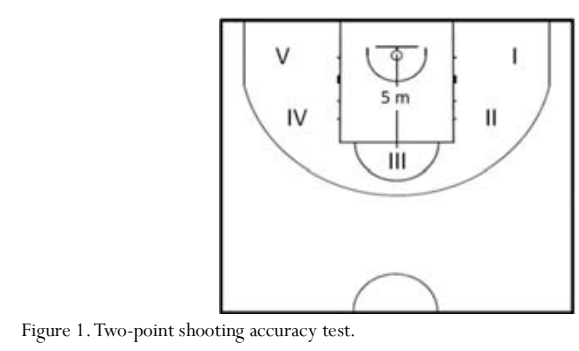

(3) Three point shooting accuracy test: each player performed three series of ten $3 \mathrm{P}$ shots from five different positions, i.e. two jump shots from each position (Figu- 
re 2). There was a three min recovery period between each shooting series. Shooting positions were marked on the floor at a distance of $6.75 \mathrm{~m}$ (adjusted from the original $6.25 \mathrm{~m}$ ) from the vertical projection of the hoop's center on the floor. Two other players, positioned below the hoop, caught the rebound and passed the ball back for a new shot. There was no time limit for performing the test.

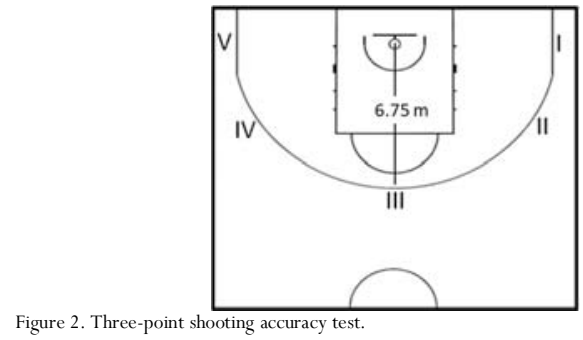

\section{Shooting Kinematics}

For basketball shooting kinematic analysis the athletes performed one series of ten FT, one series of ten $2 \mathrm{P}$ shots (from the middle and at a distance of five $\mathrm{m}$ ) and one series of ten $3 \mathrm{P}$ shots (from the middle and at a distance of $6.75 \mathrm{~m}$ ) with a three min recovery period between each shooting series. All shots were recorded using a fixed camera (Canon EOS REBEL T1i/EOS 500D, Canon, Japan) and a $35 \mathrm{~mm}$ focal length lens (Canon EF-S 18-55mm f/3.5-5.6 IS, Canon, Japan) positioned perpendicular to the line of motion and approximately eight $\mathrm{m}$ from the performance zone.

Kinovea v.0.8.15 was used to manually digitize the geometric center (GC) of the ball and to calculate the ball release parameters (RH, RA and RS). The ball's $\mathrm{GC}$ was identified by visual inspection. The distance from the player to the basket and the height of the basket were previously recorded using a tape measure and standardized with easily observable markers on the video. Subsequently, using Kinovea v.0.8.15, the distances were calibrated taking into account the real distances and the number of pixels in the video record. This calibration was performed independently for each direction (length and height). The release instant was defined as the last moment in which the ball was in contact with the player's hands and it was used to determine the RH (vertical distance between the ball's $\mathrm{GC}$ at the release instant and the floor) and the RA (angle between the floor, the ball position at the release instant and the ball position on the next frame after release). The RS was determined taking in consideration the ball's displacement in the first two frames after release and was calculated using Equation 1, where the coordinates pair $(\mathrm{x} 1, \mathrm{y} 1)$ represents the ball's position in the first frame and the pair $(x 2, y 2)$ represents the ball's position in the second frame.

Equation 1: $\operatorname{sqrt}\left((\mathrm{x} 2-\mathrm{x} 1)^{2}+(\mathrm{y} 2-\mathrm{y} 1)^{2}\right)$

This displacement was further divided by period between frames $(30 \mathrm{~Hz}=.033 \mathrm{~s})$, giving the RS.

The Kinovea v.0.8.15 software also provided the pair of coordinates $(x, y)$ corresponding to the ball's GC along time from the video recording, which were later exported to MATLAB (v. 8.3.0.532, MathWorks, Natick, MA, United States) and processed using a specific routine. This routine was responsible for normalizing the distance between the release position and the basket $(0-100 \%)$, in order to obtain a 2D trajectory, with the ball position at $1 \%$ intervals, for each shot. With this procedure done, it was possible to calculate the average trajectory between trials of the same subject, as well as to detect the most different trajectories from the average, giving the TV for each shooting series. The entire digitization process was carried out by a trained person with experience in performing this task.

We choose a 2D method for shooting motion analysis since in basketball the ball displacement is mainly in the sagittal plane and, although there is displacement in the frontal plane, this will not affect greatly the ability of the ball to go from the player to the basket. Indeed, this methodological approach has already been validated by other researchers (Paul, Lester, Foreman \& Dibble, 2016; Schurr, Marshall, Resch \& Saliba, 2017).

\section{Shooting Training Program}

The shooting training program consisted in a workload corresponding to 600 shots per week distributed as follows: 200 FT, 2002 P shots and 200 3P shots. This program lasted five weeks (3000 total shots) and it was performed as self-directed practice, i.e. outside of formal basketball practice and without any intervention or feedback from the coaches. To accomplish the training program the following indications were given: (i) to shoot 200 FT, 200 2P shots and $2003 \mathrm{P}$ shots per week, during five consecutive weeks, (ii) to shoot the $2 \mathrm{P}$ shots from outside the restrictive area, (iii) to vary the positions in the court for the $2 \mathrm{P}$ and $3 \mathrm{P}$ shots, i.e. vary the angles in relation to the basket and (iv) to perform all shots at a competitive pace. In addition to the aforementioned indications, no restrictions were imposed regarding the actions prior to shots execution (e.g., dribble, auto-pass, colleague's pass, FT shooting routine), neither regarding the distribution of the 600 shots throughout the week. It was only suggested that players should distribute the 
shots in a balanced way throughout each week, avoiding to perform the total number of shots in a single day.

\section{Data Analysis}

Results are presented through mean and standard deviation. Normality and homogeneity of variances were checked and no significant violations were noticed. However, given the small sample size, data was analysed using non-parametric techniques. The Wilcoxon signed-rank test was used to determine the presence or absence of changes in each group, whereas the Mann-Whitney $U$ test was used to determine differences between groups on preand post-training. Furthermore, Glass rank-biserial correlation (Glass, 1966) was also computed as measure of effect size. All data analysis was done using IBM SPSS 24.0 (IMB Corp., Armonk, NY) and the significance level was set at $5 \%$.

\section{Results}

The results between the pre- and post-training and between groups in T0 and T1 for shooting performance (2P, 3P and FT) are shown in Table 2. The players from the EG significantly improved their shooting performance in both $3 \mathrm{P}(\mathrm{z}=-2.37 ; p<.05$; $\mathrm{r}=.90)$ and $\mathrm{FT}(\mathrm{z}=-2.21 ; p<.05 ; \mathrm{r}=.84)$ over time. Furthermore, no significant $(p>.05)$ mean differences were found between groups on pretraining (T0) in any of the shooting performance tests. In contrast, significant differences between the two groups on post-training (T1) were found in 3P shooting performance $(\mathrm{z}=-2.80 ; p=.01 ; \mathrm{r}=.88)$ favoring the players from the EG.

Results between the pre- and post-training and between groups in T0 andT1 for shooting kinematics (RH, RA, RS and TV) are presented in Table 3 (2P), Table 4 (3P) and Table 5 (FT). The EG significantly

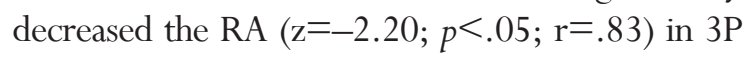
(Table 4) and significantly increased the $\mathrm{RH}(\mathrm{z}=$ 2.37; $p^{<.05 ; r=.89)}$ in FT (Table 5). The CG significantly increased the $\mathrm{RS}(\mathrm{z}=-2.20 ; p<.05 ; \mathrm{r}=.83)$ in $2 \mathrm{P}$ (Table 3). Additionally, groups were similar on pre- and post-training in all variables except for $2 \mathrm{PTV}$ $(\mathrm{z}=-1.98 ; p<.05 ; \mathrm{r}=-.63)$ in $\mathrm{T} 1$.

\section{Discussion and Implications}

In this study, we investigated the effects of a self-
Table 2.

Results between pre- and post-training and between groups in $T O$ and $T 1$ for shooting performance.

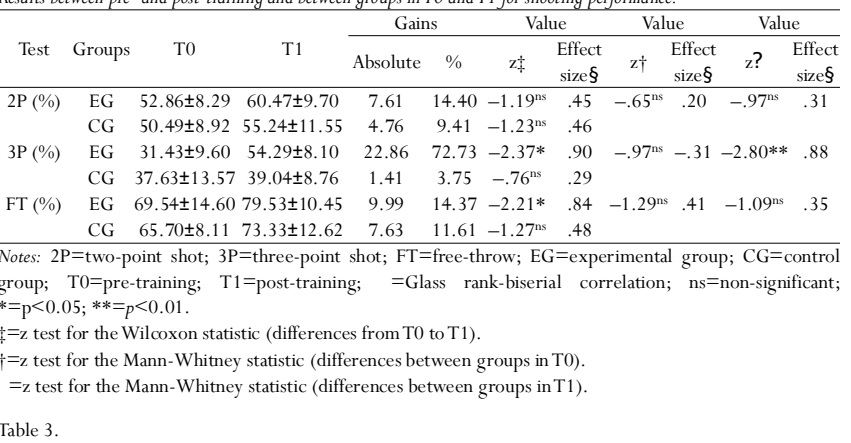

Table 3.

Results between pre- and post-training and between groups in $T O$ and $T 1$ for $2 P$ shooting kinematics.

\begin{tabular}{|c|c|c|c|c|c|c|c|c|c|c|c|}
\hline \multirow[b]{2}{*}{ Parameter } & \multirow[b]{2}{*}{ Groups } & \multirow[b]{2}{*}{ T0 } & \multirow[b]{2}{*}{$\mathrm{T} 1$} & \multicolumn{2}{|c|}{ Gains } & \multicolumn{2}{|c|}{ Value } & \multicolumn{2}{|c|}{ Value } & \multicolumn{2}{|c|}{ Value } \\
\hline & & & & Absolute & $\%$ & $\mathrm{z} \$$ & $\begin{array}{c}\text { Effect } \\
\text { size§ }\end{array}$ & $\mathrm{z}_{\dagger}^{\dagger}$ & $\begin{array}{l}\text { Effect } \\
\text { size§ }\end{array}$ & $\mathrm{z} ?$ & $\begin{array}{l}\text { Effect } \\
\text { size§ }\end{array}$ \\
\hline \multirow[t]{2}{*}{ RH (m) } & EG & $2.19 \pm .15$ & $2.21 \pm .18$ & .03 & .91 & $-1.52^{\mathrm{ns}}$ & .57 & $-.70^{\mathrm{ns}}$ & -.23 & $-.96^{\mathrm{ns}}$ & -.31 \\
\hline & CG & $2.23 \pm .12$ & $2.29 \pm .16$ & .06 & 2.69 & $-1.86^{\mathrm{ns}}$ & .70 & & & & \\
\hline \multirow[t]{2}{*}{$\mathrm{RA}\left(\left(^{\circ}\right)\right.$} & EG & $52.9 \pm 3.9$ & $52.1 \pm 2.7$ & -.9 & -1.6 & $-1.19^{\text {ns }}$ & .45 & $-1.28^{\mathrm{ns}}$ & -.41 & $-1.09^{\mathrm{ns}}$ & -.35 \\
\hline & CG & $55.1 \pm 3.3$ & $52.6 \pm 3.1$ & -2.5 & -4.5 & $-1.69^{\text {ns }}$ & .64 & & & & \\
\hline \multirow[t]{2}{*}{$\operatorname{RS}(\mathrm{m} / \mathrm{s})$} & EG & $7.27 \pm .18$ & $7.41 \pm .28$ & .15 & 1.93 & $-1.69^{\mathrm{ns}}$ & .64 & $-1.22^{\mathrm{ns}}$ & .39 & $-.06^{\mathrm{ns}}$ & .02 \\
\hline & CG & $7.10 \pm .34$ & $7.39 \pm .15$ & .29 & 4.08 & $-2.20 *$ & .83 & & & & \\
\hline \multirow[t]{2}{*}{ TV (m) } & EG & $.14 \pm .03$ & $.12 \pm .03$ & -.02 & -14.29 & $-1.52^{\mathrm{ns}}$ & .57 & $-1.47^{\mathrm{ns}}$ & -.47 & $-1.98 *$ & -.63 \\
\hline & CG & $.18 \pm .06$ & $.15 \pm .04$ & -.03 & -16.67 & $-1.01^{\mathrm{ns}}$ & .38 & & & & \\
\hline
\end{tabular}

Notes: $\mathrm{RH}=$ release height; $\mathrm{RA}=$ release angle; $\mathrm{RS}=$ release speed; $\mathrm{TV}=$ trajectory variability; $\mathrm{EG}=$ experimental group; $\mathrm{CG}=$ control group; $\mathrm{T} 0=$ pre-training; $\mathrm{T} 1=$ post-training; $=$ Glass rank-biserial correlation; $\mathrm{ns}=$ non-significant; $*=\mathrm{p}<0.05$.

correlation; $\mathrm{ns}=$ non-significant; $*=\mathrm{p}<0.05$.
$\neq=\mathrm{z}$ test for the Wilcoxon statistic (differences from T0 to T1)

$\ddagger=z$ test for the Wilcoxon statistic (differences from T0 to T1).
$\dagger=\mathrm{z}$ test for the Mann-Whitney statistic (differences between groups in T0).

$=\mathrm{z}$ test for the Mann-Whitney statistic (differences between groups in T1).

Table 4 .

Results between pre- and post-training and between groups in $T 0$ and $T 1$ for $3 P$ shooting kinematics.

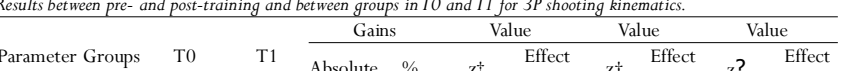

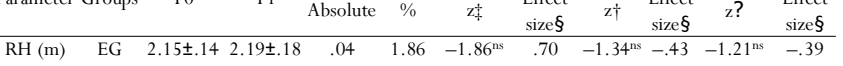

$\begin{array}{lllllllllllll} & & \text { CG } & 2.26 \pm .14 & 2.27 \pm .15 & .01 & .44 & -.68^{\mathrm{ns}} & .26 & & & & \\ \mathrm{RA}\left({ }^{\circ}\right) & \mathrm{EG} & 52.4 \pm 4.4 & 50.2 \pm 3.6 & -2.2 & -4.1 & -2.20 * & .83 & -.06^{\mathrm{ns}} & -.02 & -.06^{\mathrm{ns}} & -.02\end{array}$

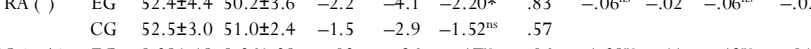

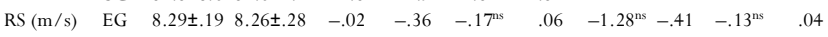

$\begin{array}{lllllllllllll} & \text { CG } & 8.39 \pm .16 & 8.26 \pm .17 & -.13 & -1.55 & -1.36^{\mathrm{ns}} & .51 & & & & \\ \mathrm{TV}(\mathrm{m}) & \mathrm{EG} & .19 \pm .08 & .17 \pm .04 & -.02 & -10.53 & -.17^{\mathrm{ns}} & .06 & -.58^{\mathrm{ns}} & -.18 & -.19^{\mathrm{ns}} & -.06\end{array}$

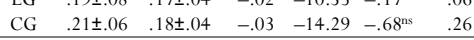

Notes: $\mathrm{RH}=$ release height; $\mathrm{RA}=$ release angle; $\mathrm{RS}=$ release speed; $\mathrm{TV}=$ trajectory variability; $\mathrm{EG}=$ experimental group; $\mathrm{CG}=$ control group; $\mathrm{T} 0=$ pre-training; $\mathrm{T} 1=$ post-training; $=$ Glass rank-biserial correlation; ns $=$ non-significant; $*=\mathrm{p}<0.05 ; * *=p<0.01$.

$\neq=\mathrm{z}$ test for the Wilcoxon statistic (differences from T0 to T1)

$\dagger=\mathrm{z}$ test for the Mann-Whitney statistic (differences between groups in T0).

$=\mathrm{z}$ test for the Mann-Whitney statistic (differences between groups in T1).

Table 5 .

Results between pre- and post-training and between groups in $T 0$ and $T 1$ for $F T$ shooting kinematice.

Paramete \begin{tabular}{llll} 
Gains & Value & Value & Value \\
\cline { 3 - 5 } & & &
\end{tabular}

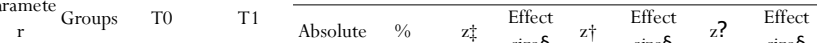

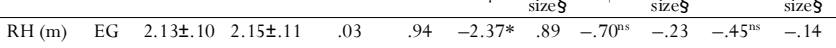

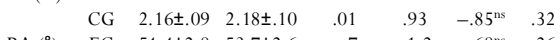

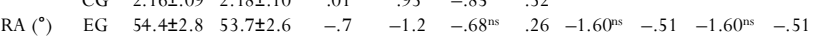

CG $57.0 \pm 3.5 \quad 56.0 \pm 2.8 \quad-1.0 \quad-1.7 \quad-1.15^{\mathrm{ns}} \quad .44$

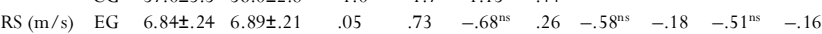

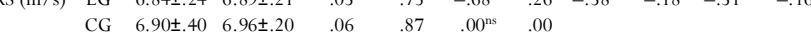

$\begin{array}{llllllllllll}\text { TV (m) } & \text { EG } & .11 \pm .02 & .11 \pm .02 & .02 & .00 & .00^{\mathrm{ns}} & .00 & -.45^{\mathrm{ns}} & -.14 & -.06^{\mathrm{ns}} & -.02\end{array}$

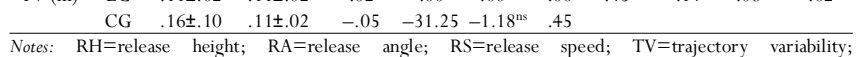
Notes: $\mathrm{RH}=$ release height; $\mathrm{RA}=$ release angle; $\mathrm{RS}=$ release speed; $\mathrm{TV}=$ trajectory variability;
$\mathrm{EG}=$ experimental group; $\mathrm{CG}=$ control group; $\mathrm{T} 0=$ pre-training; $\mathrm{T} 1=$ post-training; $=$ Glass rank-biserial correlation; ns $=$ non-significant; $*=\mathrm{p}<0.05 ; * *=p<0.01$.

$\ddagger=\mathrm{z}$ test for the Wilcoxon statistic (differences from T0 to T1).

$\dagger=\mathrm{z}$ test for the Mann-Whitney statistic (differences between groups in T0).

$=\mathrm{z}$ test for the Mann-Whitney statistic (differences between groups in T1).

shooting training program, in addition to the formal basketball practice, on shooting performance and kinematics of under-18 male basketball players. With a substantial increase of the training volume, we expected to observe changes in shooting kinematics, which could lead to an improvement in the players' shooting performance. With regards to the shooting performance, our findings revealed a significant improvement in 3P 
and FT for the EG. Despite the absence of significant differences between pre- and post-training in 2P shooting performance, the EG showed gains of $14.40 \%$ at the end of the training program, supporting the positive effect of the extra practice time on skill execution (Práxedes, González, del Villar \& Gil-Arias, 2021). On the other hand, the effects of the training program on the ball release parameters (RH, RA and RS) and on the TV deserve the following comments:

(1) Regarding the 3P shot, the improvement in the EG performance was followed by a significant decrease of the RA from $52.4 \pm 4.4^{\circ}$ to $50.2 \pm 3.6^{\circ}$. This kinematic adjustment is not consistent with other authors' results that suggest that the greater the RA of the ball during shooting, the greater the probability of success (Miller \& Bartlett, 1996; Okazaki, et al., 2015). However, literature also suggests that higher values in RA require higher force and speed production, which can result in a decrease in movement accuracy and consistency during basketball shooting (Doboviènik, et al., 2015; Okazaki, et al., 2006; Okazaki, et al., 2015). Furthermore, our results showed that this decrease of the RA in $3 \mathrm{P}$ shooting was associated with an increase of the $\mathrm{RH}$ of the ball from $2.15 \pm .14 \mathrm{~m}$ to $2.19 \pm .18 \mathrm{~m}$. Although this increase in RH was not statistically significant, it may have led to an adjustment in the players' shooting technique, which caused a decrease of the RA of the ball. Besides, the literature is unanimous in recognizing the benefit of increasing the RH of the ball for basketball shooting performance, due to the decrease of the force and speed required for technical execution (Okazaki, et al., 2006; Okazaki, et al., 2015; Tran, 2008).

(2) Concerning the FT, the improvement in the EG performance was followed by a significant increase of the RH from 2.13 $\pm .10 \mathrm{~m}$ to $2.15 \pm .11 \mathrm{~m}$. Once again, these results confirm the benefit in increasing the $\mathrm{RH}$ of the ball during shooting (Okazaki, et al., 2006; Okazaki, et al., 2015; Tran, 2008). However, this change did not significantly influence the remaining kinematic parameters under study in the FT.

(3) Regarding the $2 \mathrm{P}$ shot, no significant changes were observed in the EG ball release parameters ( $\mathrm{RH}$, RA and RS) or in the TV following shooting training. Nonetheless, in CG a significant increase of the RS of the ball during $2 \mathrm{P}$ shooting was detected.Yet, this change was not significantly reflected in the players' shooting performance, nor even in the other shooting kinematic parameters under study.

As the previous comments show, our results do not follow the initial expectations. As a matter of fact, despite the evident improvement of the EG shooting performance, very few modifications were observed in the players' shooting kinematics (RH, RA, RS and TV) at the end of the training program. Since the extra volume of shots was performed outside the formal practice, it is possible that the absence of coaching intervention has limited, in part, the magnitude of the supplementary training effect on the analysed shooting kinematic parameters. In fact, literature is unanimous in highlighting the impact that external feedback has not only on learning process, but also on technical development (Ericsson, 2008; Ericsson, Krampe \&TeschRömer, 1993; Kernodle \& Carlton, 1992;Wulf, Shea \& Lewthwaite, 2010). As mentioned by Gómez et al. (2007), skill acquisition is individual, complex and dynamic. Therefore, despite the importance of the accumulated practice time and training volume, players and coaches must always ensure the quality in each skill repetition (Ashy, Lee, \& Landin, 1988), mainly at youth categories, while creating progression strategies to achieve new skill levels (Ericsson, 2008). On the other hand, the absence of a consistent changing pattern between the kinematic parameters under study is probably also a consequence of a high inter-individual variability (Mullineaux \& Uhl, 2010), being thus possible that the EG shooting performance improvement is the result of different strategies and technical adjustments adopted by each player.

This study is not without limitations. First, due to sample specificities, we acknowledge that our sample is not widely representative. Therefore, we recommend caution when generalizing our findings. Second, we recognize that the sample size could limit the power of the statistical tests. However, previous studies in youth athletes using case study designs reported similar sample sizes. For example, Khlifa et al. (2013) only sampled 18 basketball players.

\section{Conclusions}

In conclusion, our findings showed that self-shooting basketball practice significantly improves the shooting performance of young basketball players. On the contrary, such an increase in training volume did not promote substantial changes in distinct parameters of basketball shooting kinematics (RH, RA, RS and TV). Therefore, developing shooting technique in the formal practice context seems to be determinant to excel in basketball. Once the presence of coaches' external feedback as well as the systematic practice aiming at 
the technical improvement are ensured, it is equally important to promote an increase in training volume in order to improve players' shooting performance. We recommend basketball coaches to increase shooting training volume, for example, by encouraging their players to practice this skill outside the formal basketball practice schedule, while simultaneously investing in the improvement of players' shooting technique during formal practice. Finally, future research focusing on the impact of coaches' intervention during practice on players' shooting kinematics are needed. Moreover, in order to complement this analysis, others should investigate the effects of self-shooting basketball practice on shooting kinematics from an approach that considers the player's shooting motion. Aware of the limitations of using a 2D analysis for 3D shooting motions, these future studies should also consider the use of 3D analysis for kinematics assessment.

\section{Disclosure statement}

Declarations of interest: none.

\section{References}

Ammar, A., Chtourou, H., Abdelkarim, O., Parish, A., \& Hoekelmann, A. (2016). Free throw shot in basketball: kinematic analysis of scored and missed shots during the learning process. Sport Sciencesfor Health, 12(1), 27-33. https:/ /doi.org/10.1007/s11332-015-0250-0

Ashy, M. H., Lee, A. M., \& Landin, D. K. (1988). Relationship of practice using correct technique to achievement in a motor skill. Journal of Teaching in Physical Education, 7, 115-120.https:/ /doi.org/10.1123/jtpe.7.2.115

Button, C., MacLeod, M., Sanders, R., \& Coleman, S. (2003). Examining movement variability in the basketball free-throw action at different skill levels. Research Quarterly for Exercise and Sport, 74, 257-269.https://doi.org/10.1080/ 02701367.2003.10609090

Ėauševiæ, D. (2015). Game-related statistics that discriminate winning and losing teams from the world championships in Spain in 2014. Homo Sporticus, 17(2), 16-19.

Doboviènik, L., Jakovljeviæ, S., Zovko, V., \& Erèulj, F. (2015). Determination of the optimal certain kinematic parameters in basketball three-point shooting using the 94fifty technology. Physical Culture, 69(1),5-13.https://doi.org/10.5937/ fizkul1501005D

Elliott, B. C. (1992). A kinematic comparison of the male and female two-point and three-point jump shots in basketball. Australian Journal of Science and Medicine, 24(4), 111-118.

Elliott, B. C., \&White, E. (1989).A kinematic and kinetic analysis of the female two point and three point jump shots in bas- ketball. Australian Journal of Science and Medicine, 21(2), 7-11. Ericsson, K.A. (2008). Deliberate practice and acquisition of expert performance: a general overview. Academic Emergency Medicine, 15, 988-994. https://doi.org/10.1111/j.15532712.2008.00227.x

Ericsson, K.A., Krampe, R.T., \&Tesch-Römer, C.(1993).The role of deliberate practice in the acquisition of expert performance. Psychological Review, 100(3), 363-406. https://doi.org/ 10.1037//0033-295X.100.3.363

Fazel, F., Morris, T., Watt, A., \& Maher, R. (2018). The effects of different types of imagery delivery on basketball free-throw shooting performance and self-efficacy. Psychology of Sport and Exercise, 39, 29-37. http://dx.doi.org/10.1016/ j.psychsport.2018.07.006

Gablonsky, J. M., \& Lang, A. S. I. D. (2005). Modeling basketball free throws. Society for Industrial and Applied Mathematics Review, 47(4), 775-798. https://doi.org/10.1137/ S0036144598339555

Gaetano,R., Gaetano,A.,Domenico,T.,\& Mario,L.(2016).Analysis of learning a basketball shot. Journal of Physical Education and Sport, 16(1), 3-7. https://doi.org/10.7752/ jpes. 2016.01001

García,J., Ibáñez, S.J., Santos, R.M., Leite, N., \& Sampaio,J. (2013). Identifying basketball performance indicators in regular season and playoff games. Journal of Human Kinetics, 36, 161-168. https://doi.org/10.2478/hukin-2013-0016

Glass, G.V.(1966). Note on Rank Biserial Correlation. Educational and Psychological Measurement, 26, 623f-631.https://doi.org/ $10.1177 / 001316446602600307$

Gómez, M. Á., Kreivyte, R., \& Sampaio, J. (2017). Short-and long-term effects of using shooting straps on free-throw accuracy of young female basketball players. Kinesiology, 49(2), 225-234. https://doi.org/10.26582/k.49.2.3

Hamilton, G. R., \& Reinschmidt, C. (1997). Optimal trajectory for the basketball free throw. Journal of Sports Sciences, 15, 491504. https://doi.org/10.1080/026404197367137

Hopkins, W. G., Marshall, S. W., Batterham, A. M., \& Hanin, J. (2009). Progressive statistics for studies in sports medicine and exercise science. Medicine \& Science in Sports \& Exercise, 41, 3-13. https://doi.org/10.1249/MSS.0b013e31818cb278

Ibáñez, S. J., Feu, S., García, J., Parejo, I., \& Cañadas, M. (2009). Shot differences between professional (ACB) and amateur (EBA) basketball teams. Multifactorial study. Revista de Psicología del Deporte, 18, 313-317.

Ibáñez, S. J., García, J., Feu, S., Lorenzo, A., \& Sampaio, J. (2009). Effects of consecutive basketball games on the game-related statistics that discriminate winner and losing teams. Journal of Sports Science and Medicine, 8, 458-462.

Ibáñez, S.J., Sampaio, J., Sáenz-López, P., Giménez, J., \& Janeira, M. A. (2003). Game statistics discriminating the final outcome of junior world basketball championship matches (Portugal 1999). Journal of Human Movement Studies, 45(1), 1-20.

Ibáñez, S. J., Santos, J.A., \& García, J. (2015). Multifactorial analysis of free throw shooting in eliminatory basketball games. 
International Journal Performance Analysis in Sport, 15, 897-912. https: / / doi.org/10.1080/24748668.2015.11868839

International Basketball Federation. (2014). Official Basketball Rules, Switzerland.

Kernodle, M.W., \& Carlton, L. G. (1992). Information feedback and the learning of multiple-degree-of-freedom activities. Journal of Motor Behavior, 24, 187-196.https://doi.org/ 10.1080/00222895.1992.9941614

Khlifa, R.,Aouadi, R., Shephard, R., Chelly, M. S., Hermassi, S., \& Gabbett, T. J. (2013). Effects of a shoot training programme with a reduced hoop diameter rim on free-throw performance and kinematics in young basketball players. Journal of Sports Sciences, 31(5), 497-504.https://doi.org/10.1080/ 02640414.2012.736634

Knudson, D. (1993). Biomechanics of the basketball jump shotsix key teaching points. Journal of Physical Education, Recreation and Dance, 64, 67-73. https://doi.org/10.1080/ 07303084.1993.10606710

Lorenzo,A., Gómez, M.A., Ortega, E., Ibáñez, S. J., \& Sampaio, J. (2010). Game related statistics which discriminate between winning and losing under-16 male basketball games. Journal of Sports Science and Medicine, 9, 664668.

Maymin,A.Z., Maymin, P.Z., \& Shen, E. (2012). Individual factors of successful free throw shooting. Journal of Quantitative Analysis in Sports, 8(3). https://doi.org/10.1515/1559-0410.1414

Miller, S., \& Bartlett, R. (1996). The relationship between basketball shooting kinematics, distance and playing position. Journal of Sports Sciences, 14, 243-253. https://doi.org/ 10.1080/02640419608727708

Mullineaux, D. R., \& Uhl, T. L. (2010). Coordination-variability and kinematics of misses versus swishes of basketball free throws. Journal of Sports Sciences, 28(9), 1017-1024.https: / / doi.org/10.1080/02640414.2010.487872

Okazaki,V.A., Lamas, L., Okazaki, F.A., \& Rodacki,A. L. (2013). Efeito da distância sobre o arremesso no basquetebol desempenhado por crianças [The effect of distance increase on basketball shot performed by children]. Motricidade, 9(2), 61-72. http:/ /dx.doi.org/10.6063/ motricidade.9(2).2668

Okazaki,V.H.A., \& Rodacki,A. L. F. (2012). Increased distance of shooting on basketball jump shot. Journal of Sports Science and Medicine, 11, 231-237.

Okazaki, V. H. A., Rodacki, A. L. F., \& Okazaki, F. H. A. (2006). Arremesso tipo jump no basquetebol: novatos versus experientes [The basketball jump shoot: novice versus experts]. Revista Mackenzie de Educação Física e Esporte, 5(2), 33-39.

Okazaki,V.H.A., Rodacki,A. L.F., \& Satern,M.N.(2015).A review on the basketball jump shot. Sports Biomechanics, 14(2), 190 205. https://doi.org/10.1080/14763141.2015.1052541

Paul, S., Lester, M., Foreman, K. \& Dibble, L. (2016).Validity and reliability of two dimensional motion analysis for quantifying postural deficits in adults with and without neurological impairment. The Anatomical Record, 299(9), 1165-1173. https: / / doi.org/10.1002/ar.23385

Pojskic, H., Šeparovi, V., \& U•ianin, E.(2011). Reliability and factorial validity of basketball shooting accuracy tests. Sport Scientific and Practical Aspects, 8, 25-32.

Práxedes, A., González, R., delVillar, F., \& Gil-Arias, A. (2021). Combining Physical Education and unstructured practice during school recess to improve the students' decision-making and execution (Combinando las clases de Educación Física con práctica no estructurada durante los recreos para aumentar la toma de decisiones y la ejecución de los alunos). Retos, 41, 502-511. https://doi.org/10.47197/ retos.v0i41.83455

Rojas, F.J., Cepero, M., Oña,A., \& Gutierrez, M. (2000). Kinematic adjustments in the basketball jump shot against an opponent. Ergonomics, 43(10), 1651-1660.https://doi.org/10.1080/ 001401300750004069

Ross, W. D. , \& Marfell-Jones, R. J. (1995). Cineantropometria. In J. Duncan, H. MacDougall, A. Wenger \& H. J. Green (Eds.), Evaluación fisiológica del deportista. Barcelona: Paidotribo.

Satern, M. N. (1993). Kinematic parameters of basketball jump shots projected from varying distances. Biomechanics in Sports XI. Proceedings of the XIth Symposium of the International Society of Biomechanics In Sports (pp. 313-317). Amherst-MA, USA.

Schmidt, A. (2012). Movement pattern recognition in basketball free-throw shooting. Human Movement Science, 31, 360382.https: / /doi.org/10.1016/j.humov.2011.01.003

Schurr, S.A., Marshall, A. N., Resch, J. E., \& Saliba, S. A. (2017). Two-dimensional video analysis is comparable to $3 \mathrm{D}$ motion capture in lower extremity movement assessment. International Journal of Sports Physical Therapy, 12(2), 163-172.

Tran, C. M., \& Silverberg, L. M. (2008). Optimal release conditions for the free throw in men's basketball. Journal of Sports Sciences, 26(11), 1147-1155.https://doi.org/10.1080/ 02640410802004948

Tsai, C.-Y., Ho, W.-H., Lii, Y.-K., \& Huang, C.-L. (2006). The kinematic analysis of basketball three point shoot after high intensity program. In: XXIV ISBS Symposium (pp. 276-279). Salzburg, Áustria.

Uchida, Y., Mizuguchi, N., Honda, M., \& Kanosue, K. (2014). Prediction of shot success for basketball free throws: Visual search strategy. European journal of sport science, 14(5), 426432. https://psycnet.apa.org/doi/10.1080/ 17461391.2013 .866166

Verhoeven, F. M., \& Newell, K. M. (2016). Coordination and control of posture and ball release in basketball free-throw shooting. Human movement science, 49, 216-224. https:// doi.org/10.1016/j.humov.2016.07.007

Wulf, G., Shea, C., \& Lewthwaite, R. (2010). Motor skill learning and performance: a review of inûuential factors. Medical Education, 44, 75-84.https://doi.org/10.1111/j.13652923.2009.03421.x 